\title{
Application of Advanced Land Observing Satellite 3 (ALOS-3) Data to Land Cover and Vegetation Mapping
}

\author{
Ram C. Sharma*, Hidetake Hirayama and Keitarou Hara
}

Department of Informatics, Tokyo University of Information Sciences, 4-1 Onaridai, Wakaba-ku,
Chiba 265-8501, Japan; sharma@rsch.tuis.ac.jp, hh207501@rsch.tuis.ac.jp, hara@rsch.tuis.ac.jp
${ }^{*}$ Correspondence: ram-c-sha@pm.me; Tel.: +81-43-236-4603.

Abstract: Advanced Land Observing Satellite 3 (ALOS-3) is capable of observing global land areas with wide swath $(4000 \mathrm{~km}$ along-track direction and $70 \mathrm{~km}$ cross-track direction) at high spatial resolution (panchromatic: $0.8 \mathrm{~m}$, multispectral: $3.2 \mathrm{~m}$ ). Maintenance and updating of Land Cover and Vegetation (LCV) information at national level is one of the major goals of the ALOS-3 mission. This paper presents the potential of simulated ALOS-3 images for the classification and mapping of LCV types. We simulated WorldView-3 images according to the configuration of the ALOS-3 satellite sensor and the ALOS-3 simulated (ALOS-3S) images were utilized for the classification and mapping of LCV types in two cool temperate ecosystems. This research dealt with classification and mapping of 17 classes in the Hakkoda site and 25 classes in the Zao site. We employed a Gradient Boosted Decision Tree (GBDT) classifier with 10-fold cross-validation method for assessing the potential of ALOS-3S images. In the Hakkoda site, we obtained overall accuracy, 0.811 and kappa coefficient, 0.798 . In the Zao site, overall accuracy and kappa coefficient were 0.725 and 0.711 respectively. Regardless of limited temporal scenes available in the research, ALOS-3S images showed high potential (at least 0.711 kappa-coefficient) for the LCV classification. The availability of more temporal scenes from ALOS-3 satellite is expected for improved classification and mapping of LCV types in the future.

Keywords: ALOS-3, Land Cover, Vegetation, Machine learning, Classification, Mapping, GenusPhysiognomy-Ecosystem level

\section{Introduction}

Advanced Land Observing Satellite 3 (ALOS-3) will be operated by Japan Aerospace Exploration Agency (JAXA) from 2022. The ALOS-3 satellite mission aims to deliver operational support services in the areas of disaster monitoring, updating geospatial information, and environmental monitoring. ALOS-3 is an advanced optical satellite, which carries an optical sensor complement to succeed PRISM (Panchromatic Remotesensing Instrument for Stereo Mapping) and AVNIR-2 (Advanced Visible and NearInfrared Radiometer-2) onboard the ALOS-1 satellite. It is capable of observing global land areas with a wide swath (4000 km along-track direction and $70 \mathrm{~km}$ cross-track direction) at high spatial resolution (Panchromatic: $0.8 \mathrm{~m}$, Multispectral: $3.2 \mathrm{~m}$ ). Such a wide-swath width and revisit period of 35 days is a unique characteristic of the ALOS-3 satellite sensor.

Land cover is the prominent biophysical materials at the surface of the earth such as water, vegetation, barren, and built-up areas. The monitoring of Land Cover and Vegetation (LCV) types is necessary for improved understanding of the carbon cycle and 
climate dynamics (Bounoua et al., 2002; Jung et al., 2006; Duveiller et al., 2020). It is also a key information necessary for habitat and biodiversity conservation and management practices (Xie et al., 2008; Grekousis et al., 2015).

Maintenance and updating of LCV information at national scale is one of the major goals of the ALOS-3 mission. In this research, we present the potential of simulated ALOS3 images for LCV classification and mapping by employing machine learning and crossvalidation techniques. We also discuss the advantages of ALOS-3 satellite images for highresolution LCV mapping.

\section{Materials and Methods}

\subsection{Study area}

This research was conducted in two sites, Hakkoda and Zao in Tohoku region of Japan. They represent mountainous cool temperate ecosystems in northern Japan. The location of the study sites is shown in Figure 1.

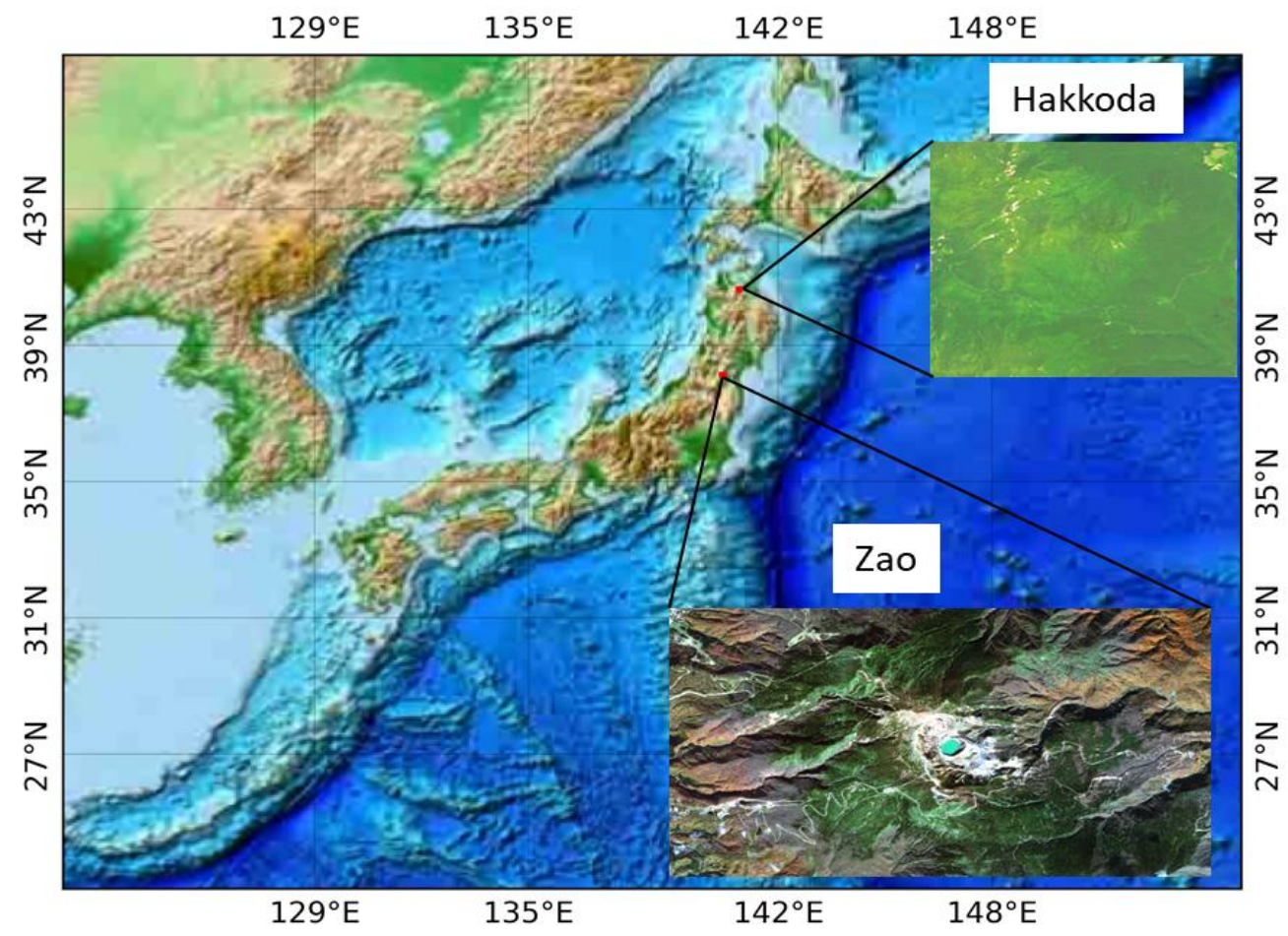

Figure 1. Location of the study sites shown by simulated ALOS-3 true-color images.

\subsection{Collection of ground truth data}

The ground truth data were prepared by field survey, with reference to existing vegetation survey map (1:25,000 scale) and visual interpretation of the time-lapse images available in Google Earth. For each LCV type, 1200-2400 sample points (longitudes and latitudes), representing a homogenous area of at least $90 \times 90 \mathrm{~m}$, were prepared for all sites concerned.

The list of LCV types dealt in the research for Hakkoda and Zao sites are shown in Tables 1 and 2 respectively. This research adopts the Genus-Physiognomy-Ecosystem (GPE) system for organization of vegetation types (Sharma, 2021). 
Table 1. List of LCV types of Hakkoda site

\begin{tabular}{cll}
\hline \multicolumn{3}{c}{ LCV classes } \\
\hline 1. Abies ECF & 10. Other ECF \\
2. Alnus DBF & 11. Other Herb \\
3. Barren & 12. Other Shrub \\
4. Betula DBF & 13. Pinus Shrub \\
5. Cryptomeria ECF & 14. Quercus DBF \\
6. Fagus DBF & 15. Quercus Shrub \\
7. Larix DCF & 16. Sasa Shrub \\
8. Miscanthus Herb & 17. Wetland Herb \\
9. Other DBF &
\end{tabular}

DBF: Deciduous Broadleaf Forest; DCF: Deciduous Conifer Forest;

ECF: Evergreen Conifer Forest; EBF: Evergreen Broadleaf Forest

Table 2. List of LCV types of Zao site

\begin{tabular}{lll}
\hline \multicolumn{2}{c}{ LCV classes } \\
\hline 1. Abies ECF & 14. Other Herb \\
2. Acer DBF & 15. Other Shrub \\
3. Alnus DBF & 16. Pinus ECF \\
4. Alpine Herb & 17. Pinus Shrub \\
5. Alpine Shrub & 18. Pterocarya DBF \\
6. Barren & 19. Quercus DBF \\
7. Betula DBF & 20. Quercus Shrub \\
8. Builtup & 21. Salix Shrub \\
9. Cryptomeria ECF & 22. Sasa Shrub \\
10. Fagus DBF & 23. Tsuga ECF \\
11. Hydrangea Shrub & 24. Water \\
12. Larix DCF & 25. Wetland Herb \\
13. Miscanthus Herb &
\end{tabular}

DBF: Deciduous Broadleaf Forest; DCF: Deciduous Conifer Forest;

ECF: Evergreen Conifer Forest; EBF: Evergreen Broadleaf Forest

\subsection{Generation of ALOS-3 images}

We acquired three cloudfree WorldView-3 scenes observed in 2015-07-07, 2016-0610, and 2019-09-20 for the Hakkoda site and two cloudfree WorldView-3 scenes observed in 2017-09-08 and 2017-10-26 for the Zao site. The WorldView-3 is a high-resolution commercial imaging satellite which acquires 11-bit data in 9 spectral bands (panchromatic, coastal, blue, green, yellow, red, red edge, near infrared 1, and near infrared 2), and additional 14-bits data in eight shortwave infrared bands. The nominal ground sample distance of the acquired images were $0.5 \mathrm{~m}$ for panchromatic and $2.0 \mathrm{~m}$ for multispectral images. We performed ortho-rectification of the WorldView-3 images (with 30m digital elevation model data) to remove geometric distortions. 
The band wise Radiometric Calibration Factor (RCF) and Effective Band Width (EBW) data were read from the metadata of the given WorldView-3 products and Top-OfAtmosphere (TOA) radiance was calculated from the pixel-wise Digital Number (DN) values using Equation (1).

$$
\text { Radiance }(T O A)=\mathrm{DN} \times \frac{\mathrm{RCF}}{\mathrm{EBW}}
$$

Then, the TOA reflectance was calculated with Earth-Sun Distance (ESD), band-averaged Solar Spectral Irradiance (Irr), and Solar Zenith Angle (SZA) using Equation (2).

$$
\text { Reflectance }(T O A)=\frac{\text { Radiance } \times E S D^{2} \times 3.1416}{\operatorname{Irr} \times \operatorname{COS}(S Z A)}
$$

Table 3 shows the band wise comparison between WorldView-3 (besides shortwave infrared bands) and ALOS-3 satellites. The observation bands between the WorldView-3 and ALOS-3 satellites are almost identical except for two bands (yellow and near infrared 2) which are not installed in ALOS-3.

Table 3. Comparison of observation bands between WorldView-3 (besides shortwave infrared bands) and ALOS-3 satellites

\begin{tabular}{lcc}
\hline \multicolumn{1}{c}{ Bands } & WorldView-3 $(\mu \mathrm{m})$ & ALOS-3 $(\mu \mathrm{m})$ \\
\hline Coastal & $0.40 \sim 0.45$ & $0.40 \sim 0.45$ \\
Blue & $0.45 \sim 0.51$ & $0.45 \sim 0.50$ \\
Green & $0.51 \sim 0.58$ & $0.52 \sim 0.60$ \\
Yellow & $0.58 \sim 0.62$ & not installed \\
Red & $0.63 \sim 0.69$ & $0.61 \sim 0.69$ \\
Red edge & $0.70 \sim 0.74$ & $0.69 \sim 0.74$ \\
Near infrared 1 & $0.77 \sim 0.89$ & $0.76 \sim 0.89$ \\
Near infrared 2 & $0.86 \sim 1.04$ & not installed \\
Panchromatic & $0.45 \sim 0.80$ & $0.52 \sim 0.76$ \\
\hline
\end{tabular}

For this research, we extracted seven bands (coastal, blue, green, red, red edge, near infrared, and panchromatic) from the WorldView-3 satellite data which will be available from the ALOS-3 satellite. The WorldView-3 imagery were resampled into the size of the ALOS3 satellite imagery $(0.80 \mathrm{~m}$ for the panchromatic and $3.2 \mathrm{~m}$ for the multi-spectral bands) using nearest neighbor method. In this manner, ALOS-3 simulated (ALOS-3S) images were generated. We calculated nine spectral vegetation indices (as shown in Table 4) for each scene.

Table 4. Spectral vegetation indices utilized in the research. 


\begin{tabular}{|c|c|c|}
\hline Indices & Formula & References \\
\hline Normalized Difference Vegetation Index (NDVI) & $\frac{N-R}{N+R}$ & Rouse et al., 1974 \\
\hline Green Red Vegetation Index (GRVI) & $\frac{G-R}{G+R}$ & Falkowski et al., 2005 \\
\hline Soil-Adjusted Vegetation Index ( SAVI ) & $\frac{1.5 \times(N-R)}{N+R+0.5}$ & Huete., 1988 \\
\hline Modified Soil Adjusted Vegetation Index (MSAVI) & $\frac{2 N+1-\sqrt{(2 N+1)^{2}-8(N-R)}}{2}$ & Qi et al., 1994 \\
\hline Atmospherically Resistant Vegetation Index (ARVI) & $\frac{N-R-(R-B)}{N+R-(R-B)}$ & $\begin{array}{l}\text { Kaufman and Tanre, } \\
1992\end{array}$ \\
\hline $\begin{array}{l}\text { Modified Chlorophyll Absorption Ratio Index } \\
\text { (MCARI) }\end{array}$ & $\{(R E-R)-0.2(R E-G)\}(R E / R)$ & Daughtry et al., 2000 \\
\hline Non-Homogeneous Feature Difference ( NHFD ) & $\frac{R E-C}{R E+C}$ & Wolf, 2012 \\
\hline Structure-Insensitive Pigment Index ( SIPI ) & $\frac{N-B}{N-R}$ & Penuelas et al., 1995 \\
\hline Enhanced Vegetation Index (EVI) & $2.5 \frac{N-R}{(N+6 R-7.5 B)+1}$ & Huete et al., 2002 \\
\hline
\end{tabular}

The multi-temopral features comprising of spectral and vegetation indices were prepared for machine learning. It consists of 48 features ( 3 observations $\times 16$ bands) for the Hakkoda site and 32 features ( 2 observations $\times 16$ bands) for the Zao site.

\subsection{Machine learning and mapping}

The pixel values, corresponding to the ground truth (geolocation points) data for each LCV type were extracted from the ALOS-3S images. GBDT classifier with 10-fold crossvalidation method was employed to assess the potential of ALOS-3S images for LCV classification. Classification accuracy metrics, such as overall accuracy, kappa coefficient, f1-score, recall, and precision were calculated for the model assessment. Finally, we trained the model on $95 \%$ data for the prediction (mapping) of LCV types.

\section{Results and Discussion}

\subsection{Confusion matrices}

The confusion matrix calculated with a 10-fold cross-validation method for the Hakkoda site has been shown in Figure 2. 


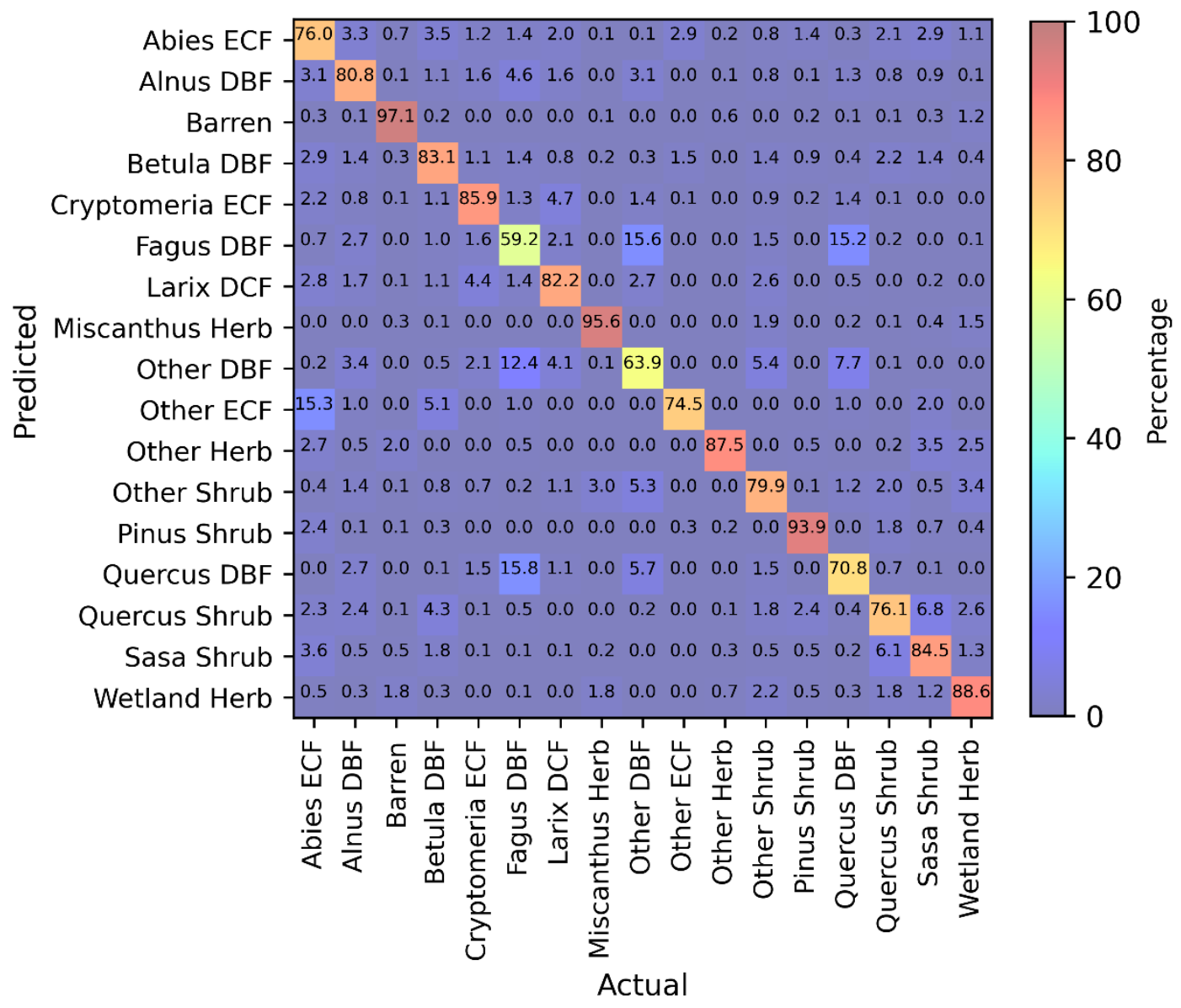

Figure 2. The confusion matrix computed for the Hakkoda site.

The confusion matrix calculated with 10-fold cross-validation method for the Zao site has been shown in Figure 3. 


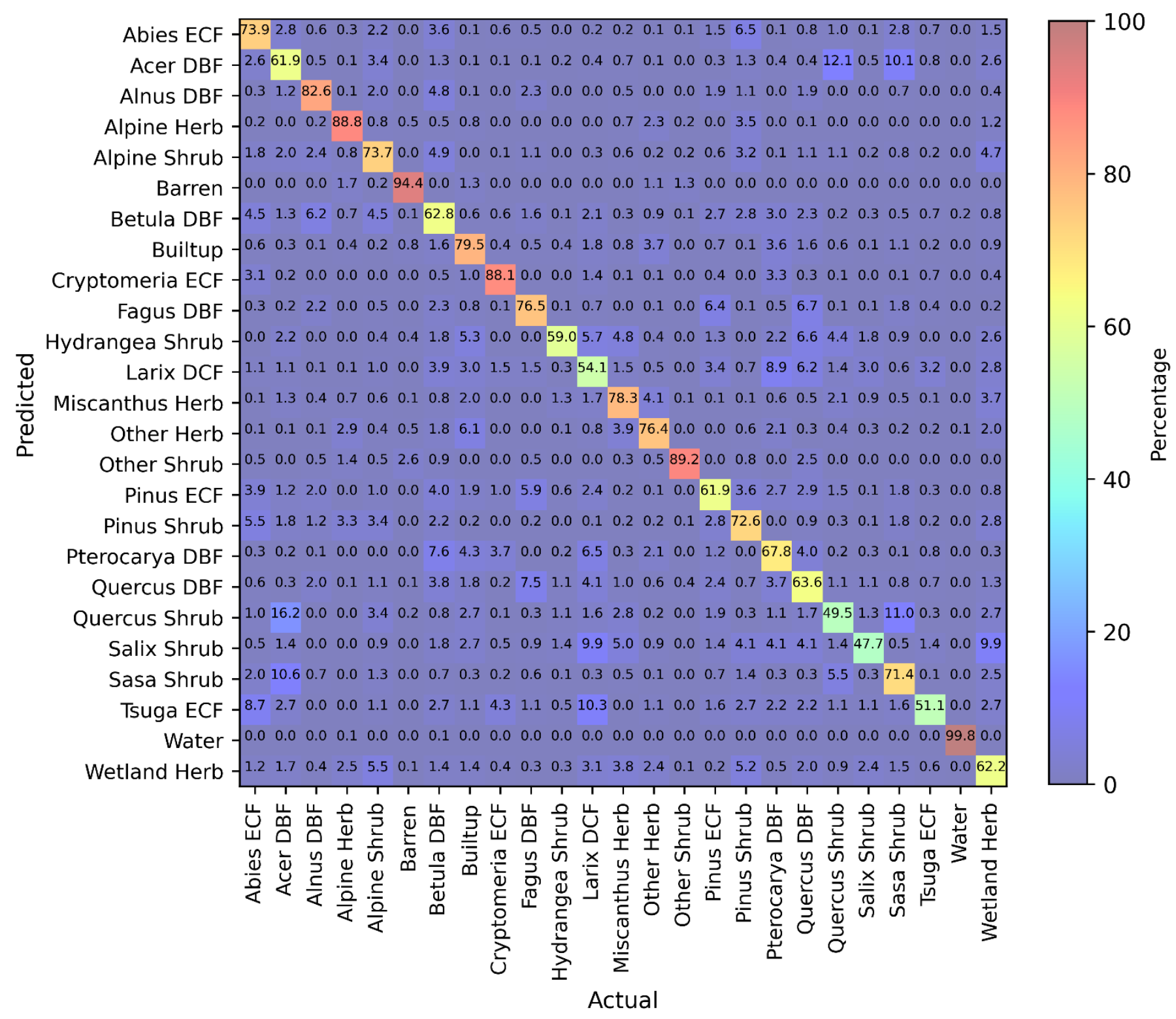

Figure 3. The confusion matrix computed for the Zao site.

\subsection{Class wise accuracies}

The class-wise accuracy obtained from the 10-fold cross validation method has been shown in Tables 5 and 6 for Hakkoda and Zao sites respectively. Though most of the classes were discriminated satisfactorily, weak classification of some classes, for instance Salix Shrub and Tsuga ECF in site Zao (Table 6) were detected.

Table 5. Class wise accuracy obtained for the Hakkoda site.

\begin{tabular}{lrrrrr}
\hline Class & Accuracy & Kappa & F1-score & Precision & Recall \\
\hline Abies ECF & 0.969 & 0.750 & 0.766 & 0.760 & 0.773 \\
Alnus DBF & 0.974 & 0.785 & 0.799 & 0.808 & 0.789 \\
Barren & 0.995 & 0.960 & 0.963 & 0.971 & 0.955 \\
Betula DBF & 0.978 & 0.820 & 0.832 & 0.831 & 0.834 \\
Cryptomeria ECF & 0.981 & 0.847 & 0.857 & 0.859 & 0.854
\end{tabular}




\begin{tabular}{llllll} 
Fagus DBF & 0.947 & 0.570 & 0.598 & 0.592 & 0.605 \\
Larix DCF & 0.977 & 0.811 & 0.823 & 0.822 & 0.824 \\
Miscanthus Herb & 0.994 & 0.947 & 0.951 & 0.956 & 0.945 \\
Other DBF & 0.953 & 0.621 & 0.646 & 0.639 & 0.654 \\
Other ECF & 0.996 & 0.543 & 0.545 & 0.745 & 0.429 \\
Other Herb & 0.997 & 0.884 & 0.885 & 0.875 & 0.895 \\
Other Shrub & 0.973 & 0.777 & 0.792 & 0.799 & 0.785 \\
Pinus Shrub & 0.992 & 0.933 & 0.937 & 0.939 & 0.936 \\
Quercus DBF & 0.962 & 0.686 & 0.706 & 0.708 & 0.704 \\
Quercus Shrub & 0.971 & 0.774 & 0.789 & 0.761 & 0.820 \\
Sasa Shrub & 0.979 & 0.827 & 0.838 & 0.845 & 0.832 \\
Wetland Herb & 0.984 & 0.871 & 0.879 & 0.886 & 0.872 \\
\hline
\end{tabular}

Table 6. Class wise accuracy obtained for the Zao site.

\begin{tabular}{|c|c|c|c|c|c|}
\hline Class & Accuracy & Kappa & F1-score & Precision & Recall \\
\hline Abies ECF & 0.972 & 0.723 & 0.738 & 0.739 & 0.736 \\
\hline Acer DBF & 0.960 & 0.614 & 0.635 & 0.619 & 0.652 \\
\hline Alnus DBF & 0.981 & 0.818 & 0.827 & 0.826 & 0.829 \\
\hline Alpine Herb & 0.989 & 0.888 & 0.894 & 0.888 & 0.900 \\
\hline Alpine Shrub & 0.972 & 0.718 & 0.733 & 0.737 & 0.730 \\
\hline Barren & 0.998 & 0.931 & 0.933 & 0.944 & 0.921 \\
\hline Betula DBF & 0.958 & 0.564 & 0.586 & 0.628 & 0.550 \\
\hline Builtup & 0.977 & 0.767 & 0.779 & 0.795 & 0.764 \\
\hline Cryptomeria ECF & 0.989 & 0.887 & 0.892 & 0.881 & 0.904 \\
\hline Fagus DBF & 0.976 & 0.771 & 0.783 & 0.765 & 0.802 \\
\hline Hydrangea Shrub & 0.996 & 0.469 & 0.471 & 0.590 & 0.392 \\
\hline Larix DCF & 0.952 & 0.604 & 0.629 & 0.541 & 0.752 \\
\hline Miscanthus Herb & 0.980 & 0.808 & 0.819 & 0.783 & 0.859 \\
\hline Other Herb & 0.984 & 0.715 & 0.723 & 0.764 & 0.686 \\
\hline Other Shrub & 0.998 & 0.887 & 0.888 & 0.892 & 0.884 \\
\hline Pinus ECF & 0.976 & 0.541 & 0.553 & 0.619 & 0.500 \\
\hline Pinus Shrub & 0.971 & 0.715 & 0.731 & 0.726 & 0.736 \\
\hline Pterocarya DBF & 0.966 & 0.665 & 0.683 & 0.678 & 0.688 \\
\hline Quercus DBF & 0.961 & 0.626 & 0.646 & 0.636 & 0.657 \\
\hline Quercus Shrub & 0.968 & 0.484 & 0.501 & 0.495 & 0.507 \\
\hline Salix Shrub & 0.993 & 0.281 & 0.284 & 0.477 & 0.202 \\
\hline Sasa Shrub & 0.968 & 0.685 & 0.702 & 0.714 & 0.690 \\
\hline Tsuga ECF & 0.993 & 0.263 & 0.266 & 0.511 & 0.179 \\
\hline Water & 1.000 & 0.996 & 0.996 & 0.998 & 0.994 \\
\hline Wetland Herb & 0.973 & 0.533 & 0.547 & 0.622 & 0.487 \\
\hline
\end{tabular}

3.3. Performance summary

The performance of ALOS-3(S) images on the classification of LCV types has been summarized in Table 7. 
Table 7. Performance of ALOS-3S images

\begin{tabular}{llllll}
\hline Sites & Overall accuracy & Kappa coefficient & F1-score & Recall & Precision \\
\hline Hakkoda & 0.811 & 0.798 & 0.811 & 0.811 & 0.811 \\
Zao & 0.725 & 0.711 & 0.725 & 0.725 & 0.725 \\
\hline
\end{tabular}

\subsection{Production of LCV maps}

The 17-class LCV map produced for the Hakkoda site has been shown in Figure 4. Similarly, Figure 5 shows a 25-class LCV map produced for the Zao site.

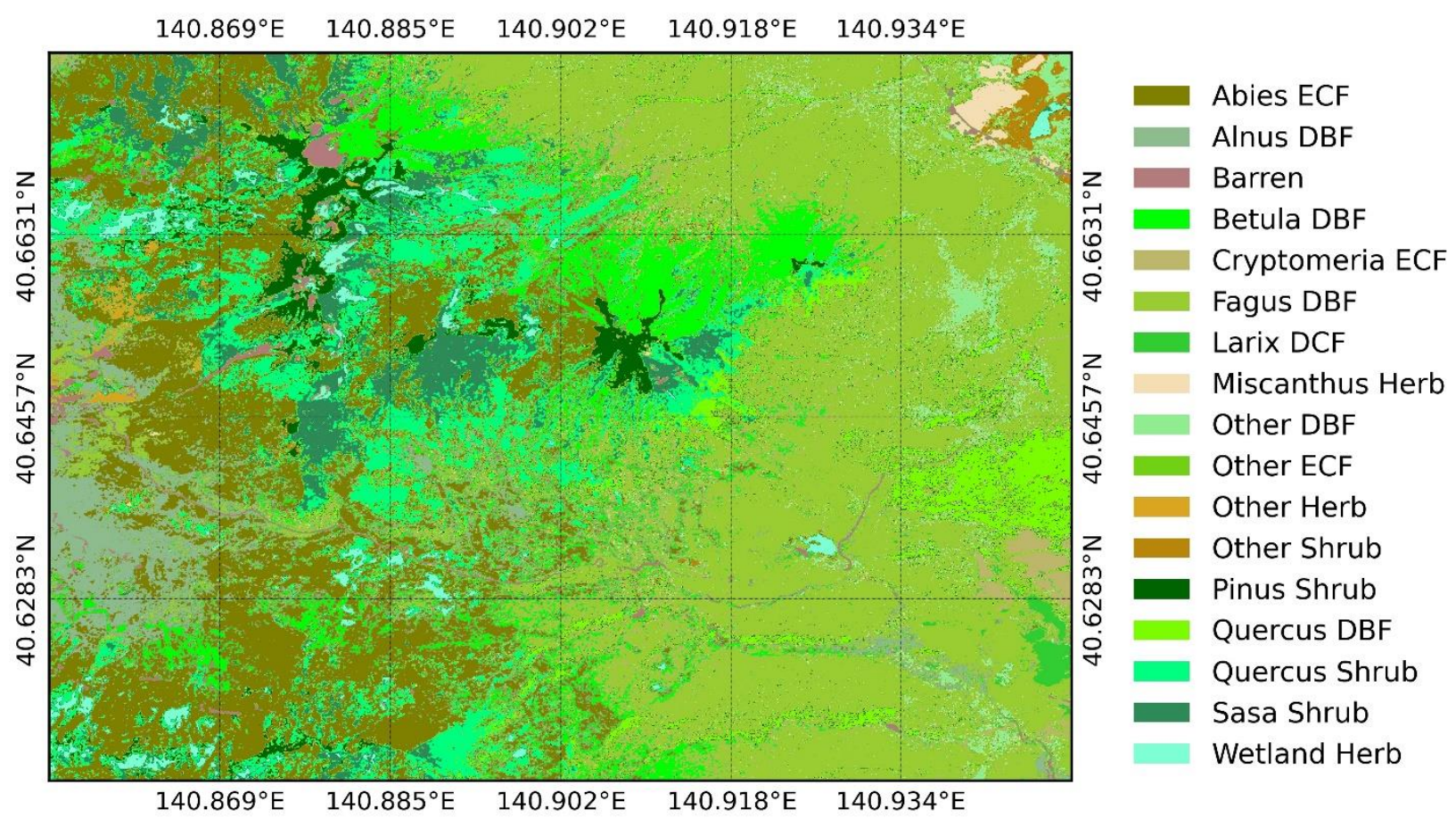

Figure 4. 17-class LCV map of Hakkoda site using ALOS-3S images.

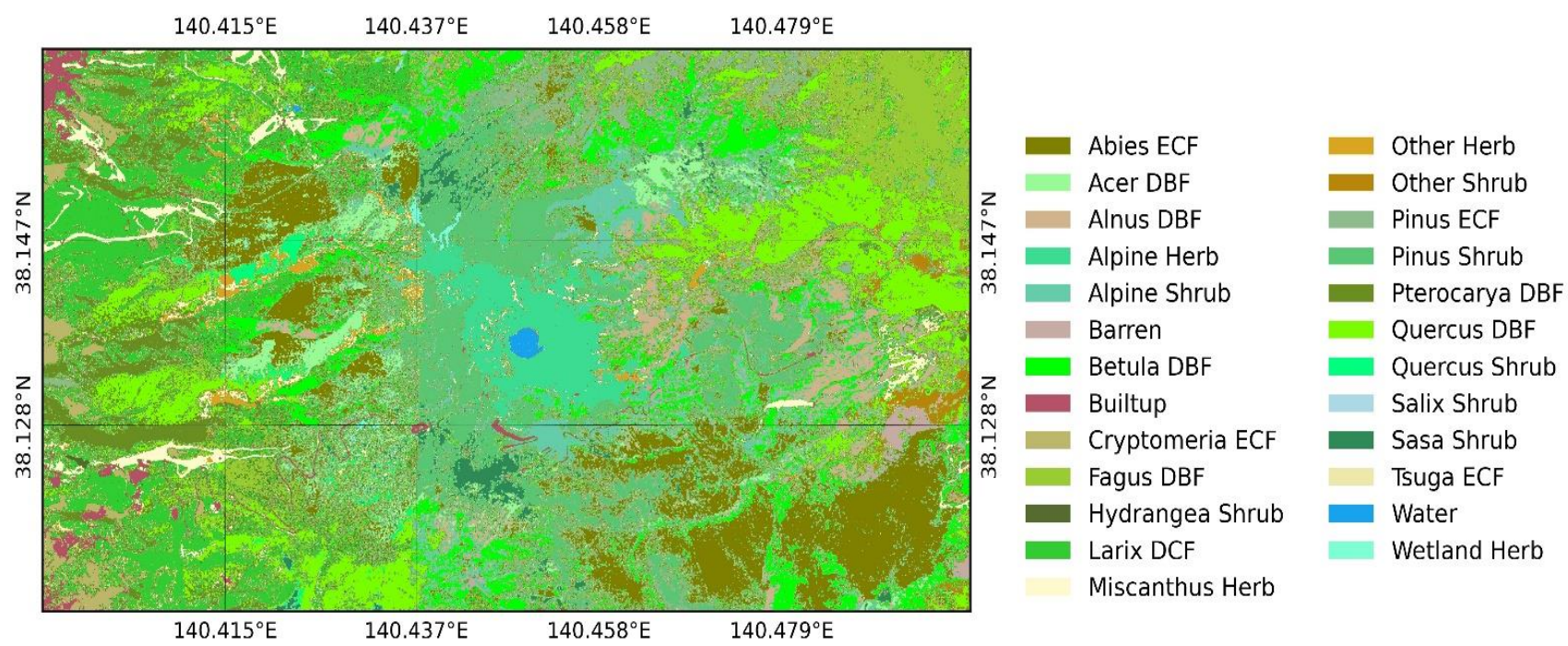

Figure 5. 25-class LCV map of Zao site using ALOS-3S images. 
We performed classification and mapping of LCV types by employing machine learning techniques on ALOS-3S images. However, the confusion matrices in Figures 2 and 3 showed that there were some misclassifications. The availability of more cloud free temporal scenes is expected to utilize seasonal information and improve the accuracy further. The ALOS-3 satellite is also capable of stereoscopic observation mode (acquires stereo-pair image from two different directions) and offers the possibility of generating digital surface models (DSMs) at fine scale. The high-resolution DSMs data generated from multiple pairs of stereo images are expected for further enhancing the classification accuracy of LCV types. Larger the spatial and temporal resolutions of the satellite data, higher the data volume. However, implementation of parallel processing of the satellite data and machine learning with Compute Unified Device Architecture (CUDA) computations offers rapid processing and analysis even with the workstation computers. ALOS-3 images with $3.2 \mathrm{~m}$ spatial resolution should be able to grasp the vegetation information at individual tree level. It should contribute to ecological understanding and conservation of narrow range plant communities. Acquisition of images with wider coverage should be beneficial to LCV classification and mapping against the images acquired from narrow swath satellites in different weather conditions.

\section{Conclusion}

Seamless observation of global land surface with 35-day revisit period by ALOS-3 satellite will be one of the highest capacities available for the high-resolution (panchromatic $0.8 \mathrm{~m}$, multi-spectral $3.2 \mathrm{~m}$ ) satellites. In this research, we assessed the potential of ALOS-3S images with limited temporal scenes for the classification and mapping of LCV types. Achieving at least $71 \%$ classification accuracy in terms of kappa coefficient with limited temporal scenes is promising. Availability of more temporal scenes from the ALOS-3 satellite is expected for delivering improved LCV maps in the future.

Author Contributions: R. Sharma performed the research and wrote the manuscript. H. Hirayama supported the research and analysis. K. Hara supervised the research. All authors have read and agreed to the published version of the manuscript.

Funding: This research was conducted under the framework of JAXA commissioned research (Application of ALOS-3 satellite data to vegetation mapping in 2019). The preparation of ground truth data was supported by the commissioned research of the Ministry of the Environment, Center for Biodiversity and Asia Air Survey Co., Ltd. This research was partially supported by JSPS Grant-inAid for Scientific Research (JP19H04320).

Acknowledgments: Copyright of the WorldView-3 data is inherited to Maxar (formally DigitalGlobe).

Conflicts of Interest: The authors declare no conflict of interest.

\section{References}

1. Bounoua, L.; DeFries, R.; Collatz, G.J.; Sellers, P.; Khan, H. Effects of Land Cover Conversion on Surface Climate. Climatic Change 2002, 52, 29-64, doi:10.1023/A:1013051420309. 
2. Daughtry, C. Estimating Corn Leaf Chlorophyll Concentration from Leaf and Canopy Reflectance. Remote Sensing of Environment 2000, 74, 229-239, doi:10.1016/S0034-4257(00)00113-9.

3. Duveiller, G.; Caporaso, L.; Abad-Viñas, R.; Perugini, L.; Grassi, G.; Arneth, A.; Cescatti, A. Local Biophysical Effects of Land Use and Land Cover Change: Towards an Assessment Tool for Policy Makers. Land Use Policy 2020, 91, 104382, doi:10.1016/j.landusepol.2019.104382.

4. Falkowski, M.J.; Gessler, P.E.; Morgan, P.; Hudak, A.T.; Smith, A.M.S. Characterizing and Mapping Forest Fire Fuels Using ASTER Imagery and Gradient Modeling. Forest Ecology and Management 2005, 217, 129-146, doi:10.1016/j.foreco.2005.06.013.

5. Grekousis, G.; Mountrakis, G.; Kavouras, M. An Overview of 21 Global and 43 Regional Land-Cover Mapping Products. International Journal of Remote Sensing 2015, 36, 5309-5335, doi:10.1080/01431161.2015.1093195.

6. Huete, A.; Didan, K.; Miura, T.; Rodriguez, E.P.; Gao, X.; Ferreira, L.G. Overview of the Radiometric and Biophysical Performance of the MODIS Vegetation Indices. Remote Sensing of Environment 2002, 83, 195-213, doi:10.1016/S0034-4257(02)00096-2.

7. Huete, A.R. A Soil-Adjusted Vegetation Index (SAVI). Remote Sensing of Environment 1988, 25, 295-309, doi:10.1016/0034-4257(88)90106-X.

8. Jung, M.; Henkel, K.; Herold, M.; Churkina, G. Exploiting Synergies of Global Land Cover Products for Carbon Cycle Modeling. Remote Sensing of Environment 2006, 101, 534-553, doi:10.1016/j.rse.2006.01.020.

9. Kaufman, Y.J.; Tanre, D. Atmospherically Resistant Vegetation Index (ARVI) for EOS-MODIS. IEEE Trans. Geosci. Remote Sensing 1992, 30, 261-270, doi:10.1109/36.134076.

10. Penuelas, J.; Frederic, B.; Filella, I. Semi-Empirical Indices to Assess Carotenoids/Chlorophyll-a Ratio from Leaf Spectral Reflectance. Photosynthetica 1995, 31, 221-230.

11. Qi, J.; Chehbouni, A.; Huete, A.R.; Kerr, Y.H.; Sorooshian, S. A Modified Soil Adjusted Vegetation Index. Remote Sensing of Environment 1994, 48, 119-126, doi:10.1016/0034-4257(94)90134-1.

12. Rouse, J.W.; Haas, R.H.; Schell, J.A.; Deering, D.W. Monitoring Vegetation Systems in the Great Plains with ERTS. NASA special publication 1974, 351, 309.

13. Sharma, R.C. Genus-Physiognomy-Ecosystem (GPE) System for Satellite-Based Classification of Plant Communities. Ecologies 2021, 2, 203-213, doi:10.3390/ecologies2020012.

14. Wolf, A.F. Using WorldView-2 Vis-NIR Multispectral Imagery to Support Land Mapping and Feature Extraction Using Normalized Difference Index Ratios.; Shen, S.S., Lewis, P.E., Eds.; Baltimore, Maryland, May $12012 ;$ pp. $83900 \mathrm{~N}-83900 \mathrm{~N}-8$.

15. Xie, Y.; Sha, Z.; Yu, M. Remote Sensing Imagery in Vegetation Mapping: A Review. Journal of Plant Ecology 2008, 1, 9-23, doi:10.1093/jpe/rtm005. 